\title{
INFORMÁTICA Y JUSTICIA EN EL PERÚ
}

\author{
EDGARDO TORRES LÓPEZ*
}

\begin{abstract}
Resumen
El desarrollo de la tecnología informática, alcanza todos los ámbitos del conocimiento y la acción humana, la justicia no es la excepción; la informática judicial posibilita que juzgados de determinadas especialidades abarrotados con expedientes físicos, se conviertan en juzgados modernos que imparten justicia con el sustento de expedientes virtuales, en los que predomina, la oralidad, la calidad y el tiempo oportuno.

El Poder Judicial de Perú, así como otros países latinoamericanos, progresivamente se encamina a ese objetivo, con los avances realizados en notificaciones electrónicas y video audiencias.
\end{abstract}

Palabras clave: Informática judicial - Informática de gestión - Video audiencia.

\begin{abstract}
Information technology development extends over all knowledge areas and human action. Justice is not an exception. Legal information technology facilitates specific court areas packed with physical files to become modern courts, administering justice using virtual files, where orality, quality and proper time stand out.

The Peruvian Judiciary, as well as that of other Latin American countries, is heading towards this goal progressively, by the progress made in electronic service of process and video hearings.
\end{abstract}

Key words: Judicial information technology - Management information Video hearing.

\section{Sumario}

1. Antecedentes. 2. Informática judicial. 3. Video audiencias. 4. Video audiencias en el Perú. 5. Base legal. 6. Resolución de video audiencia judicial. 7. Otras video audiencias realizadas.

\footnotetext{
* Juez Superior Titular de la Corte Superior de Justicia de Lima Norte - Poder Judicial de Perú.
} 


\section{ANTECEDENTES}

La tecnología es el conjunto de conocimientos técnicos, sistemáticamente organizados, que se acrecientan con la inteligencia y esfuerzo humano y se perfeccionan constantemente con el desarrollo de la sociedad.

Uno de los sorprendentes avances de la tecnología es la video conferencia, que permite la comunicación a cualquier parte del mundo en forma inmediata, viendo y oyendo al interlocutor.

Actualmente es posible efectuar por internet ${ }^{1}$ transferencias de datos, imágenes, sonidos, vídeos, así como su reproducción y almacenamiento, en forma automática.

Asimismo, continúa desarrollando la transmisión a distancia de imágenes en tercera dimensión como si fueran reales.

Adicionalmente es común el uso de teléfonos celulares, para la comunicación con cualquier lugar del mundo; todos estos avances se relacionan con la informática.

\section{INFORMÁTICA JUDICIAL}

La informática judicial es la aplicación de los sistemas electrónicos y telemáticos que posibilitan la información automática, en las actividades judiciales.

La informática judicial, constituye parte del proceso de modernización de la justicia; usando medios tecnológicos que generan nuevos sistemas de administración, gestión y decisión; redes de interconexión nacional e internacional; bases de datos; expedientes electrónicos; reconstrucción virtual de casos, control biométrico de firmas de sentenciados y procesados; digitalización de archivos; video audiencias y otros.

La informática judicial consiste en el aprovechamiento pleno de los recursos electrónicos y telemáticos, mediante el uso de redes (internet, extranet, intranet) para la solución de procesos, en la comunicación, la información, organización y decisión respectiva.

El conocido empresario Bill Gates en el libro "Los negocios en la era digital", expresa: "en el Poder Judicial, los sistemas de control de flujos de trabajo basados en PC han hecho posible que los tribunales de Estados Unidos y Canadá pasen los sumarios al procedimiento electrónico. Por ejemplo en el Condado 
de León (Florida) existe un sistema por el cual las partes pueden iniciar causas directamente vía e-mail, transfiriendo todos los escritos al sistema de gestión electrónico y recibiendo a vuelta de e-mail el número de sumario. Atendiendo además que muchas actas judiciales son documentos públicos, el Condado quiere situarlos en la red para información de las partes y del público".

Asimismo en Panamá, la justicia comercial usa el expediente electrónico; igual ocurre en algunos estados de Brasil.

En el Poder Judicial de Perú, progresivamente se ha empezado a usar la informática de gestión, en el desarrollo de la justicia, en lo que se refiere a notificaciones electrónicas, video audiencias, firmas biométricas; en un futuro próximo se logrará como meta el expediente virtual, en procesos no contenciosos, caso de reconocimiento de sentencias expedidas en el extranjero (exequatur), que podrán ser planteados directamente por internet.

\section{VIDEO AUDIENCIAS}

La video audiencia como sistema de comunicación interactivo, permite la transmisión simultánea de imagen, sonido y datos, posibilitando una comunicación bidireccional plena en tiempo real. Es decir, hace realidad la reunión de diferentes personas ubicadas geográficamente en lugares diferentes y distantes entre sí. En otros términos, la video audiencia es un instrumento técnico que permite, lo que la doctrina italiana denomina "proceso a distancia", en el que la práctica de la prueba (testifical, pericial, etc.) se realiza sin la presencia física del testigo, perito, acusado ante la sede del juzgado instructor o tribunal; pero sí con su imagen y voz desde la distancia en tiempo real, cumpliendo los principios de inmediación, eficacia, economía, celeridad y justicia oportuna.

De otro lado, las video audiencias posibilitan una actuación directa, sin necesidad de mandatos y poderes por escrituras públicas o consulares; genera la integración judicial entre autoridades y ciudadanos peruanos residentes en diversos países del mundo; finalmente, contribuye a lograr celeridad procesal, eficacia, justicia y principalmente un notable ahorro de costos económicos, de esfuerzos y de tiempo.

\section{VIDEO AUDIENCIAS EN EL PERÚ}

La Corte Superior de Lima Norte fue la primera en el Perú que utilizó internet en el desarrollo de video audiencias en procesos judiciales; posteriormente han seguido con éxito, las Corte Superior de Justicia de Huaura. Un breve recuento histórico es el siguiente: 
El Sexto Juzgado de Familia de Lima Norte, que dirigía el doctor Luis Alberto Salinas Bernal, el día 15 de diciembre de 2006, en el Expediente $N^{\circ}$ 23112005, efectuó la primera video audiencia, con la intervención virtual de una demandada, residente en los Estados Unidos de Norteamérica, en un caso de adopción de un menor. Dicho acto fue un hecho histórico sin precedentes en la administración de justicia y abrió el camino para el uso regular del video en las audiencias judiciales en asuntos de derecho de familia, para evitar el desplazamiento nacional e internacional de numerosos justiciables en casos vinculados a dicha materia.

\section{BASE LEGAL}

- Ley N²7419, del 25 de enero de 2001, Ley sobre Notificación por Correo Electrónico. Modifica los artículos $163^{\circ}$ y $164^{\circ}$ del Código Procesal Civil, notificación de los procesos judiciales por correo electrónico.

- Ley $\mathrm{N}^{\circ} 27444$, del10deabrilde2001,Ley deProcedimientos Administrativos Generales, artículo $20^{\circ}$, autoriza el uso de correo electrónico.

- Ley $N^{\circ} 27291$, del 23 de junio de 2002. Modifica los artículos $141^{\circ}$ y $1374^{\circ}$ del Código Civil; así mismo, añade el artículo 141-A, permitiendo la utilización de los medios electrónicos para la manifestación de voluntad y la utilización de la firma electrónica.

- D.S. $N^{\circ}$ 060-2001-PCM (01 de junio de 2001). Dispone que es necesario el uso de nuevas tecnologías con la finalidad de modernizar la administración pública para brindar a la ciudadanía mejores servicios y una mejor imagen del Estado.

- Carta de derechos de las personas ante la justicia en el ámbito judicial iberoamericano:

Artículo $22^{\circ}$ : todas las personas tienen derecho a comunicarse con los órganos jurisdiccionales a través del correo electrónico, videoconferencia y otros medios telemáticos con arreglo a lo dispuesto en las leyes procesales.

a) Los poderes públicos impulsarán el empleo y aplicación de estos medios en el desarrollo de la actividad de los órganos jurisdiccionales así como en las relaciones de esta con todas las personas. 
b) Los documentos emitidos por los órganos jurisdiccionales y por los particulares mediante medios electrónicos y telemáticos, en soportes de cualquier naturaleza, tendrán plena validez y eficacia siempre que quede acreditada su integridad y autenticidad de conformidad con los requisitos exigidos en las leyes.

- Resolución de Presidencia N²52-2005-CSJCNL/PJ; Corte Superior de Justicia de Lima Norte. Inicio del plan piloto de notificaciones electrónicas en las salas civiles de esta sede.

\section{RESOLUCIÓN DE LA VIDEO AUDIENCIA JUDICIAL, SEXTO JUZGADO DE FAMILIA}

\section{RESOLUCIÓN NUMERO ONCE}

Independencia, diecinueve de enero del año dos mil siete.

\section{Expediente $N^{\circ} 506-2005$}

Los artículos $163^{\circ}$ y $164^{\circ}$ del Código Procesal Civil, autorizan el uso de las notificaciones electrónicas y otros medios tecnológicos; ello concordado con el artículo V del Título Preliminar del Código acotado, que a la letra dice: Las audiencias y medios probatorios se realizan ante el Juez, siendo indelegables bajo sanción de nulidad, debiendo actuar con celeridad procesal. Así mismo debe tenerse presente lo prescrito en el artículo IX del Título Preliminar del Código Procesal Civil que indica "[...] el juez adecuará la exigencia de las formas, al logro de los fines del proceso; también debe tenerse presente lo establecido en el artículo $22^{\circ}$ de la Carta de Derechos de las Personas ante la Justicia en el Espacio Judicial Iberoamericano de Presidentes de Cortes Supremas y Tribunales Supremos de Justicia, (México 2002) que establece: Todas las personas tienen derecho a comunicarse con los órganos jurisdiccionales a través del correo electrónico, videoconferencia y otros medio telemáticos con arreglo a lo dispuesto en las leyes procesales. Por tanto estando a lo solicitado y al amparo de las normas citadas. SE RESUELVE: AUTORIZAR LA VIDEO AUDIENCIA solicitada por la apoderada de los adoptantes, debiendo cumplirse con notificarlos a su correo electrónico para que participen por dicho medio en la fecha fijada para la audiencia, debiendo comunicarse a la Oficina de Administración para que brinde el apoyo logístico necesario. Notifíquese". 


\section{OTRAS VIDEO AUDIENCIAS REALIZADAS}

En agosto y noviembre de 2008, la Segunda Sala Civil de Lima Norte, que integraron en ese año los magistrados Edgardo Torres López, Hilda Huerta Ríos, y José Aliaga Rengifo, con el apoyo de la relatora Vilma Orozco Cruz y el asistente Javier Cadillo, realizaron dos video audiencias, en procesos de reconocimiento judicial de sentencia extranjeras exequatur (sentencias de divorcio expedidas, en Japón y Venezuela).

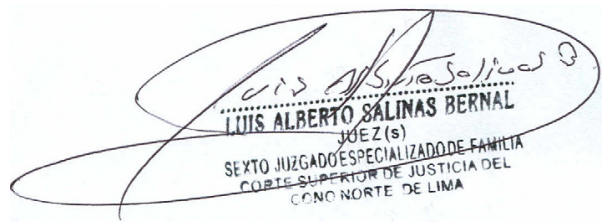

Robinson Falcón

Secretario

En diciembre de 2008, María Zapata Jaén, Juez del Segundo Juzgado de Familia de Lima Norte, efectuó una video audiencia en un proceso de familia para recibir la declaración de un testigo.

Asimismo, en marzo de 2009, Jessica Campos Martínez, Jueza del Segundo Juzgado Penal de Lima Norte, mediante videoconferencia tomó la declaración de un testigo que se encuentra en la ciudad de Madrid, España, como parte de un proceso judicial por delito contra el pudor.

En junio de 2009, Carlos Humala Trigoso, Juez de Investigación Preparatoria de la Corte Superior de Justicia de Huaura, sentenció por video audiencia, a Milagros Rosalina Pablo Olórtegui ciudadana peruana residente en Milán, Italia; por los delitos de estafa y asociación ilícita para delinquir en agravio de la Oficina de Normalización Previsional (ONP).

La condena que impuso fue 3 años de pena privativa de la libertad suspendida; con un periodo de prueba de dos años; se fijaron reglas de conducta. Asimismo impuso cinco mil soles (S/. 5,000.00) de reparación civil; el incumplimiento de la sentencia puede dar lugar a pena privativa de la libertad efectiva.

La sentenciada Milagros Rosalina Pablo Olórtegui manifestó su conformidad con la resolución judicial; el asesor legal de la ONP, apeló el monto de la reparación civil fijada. La video audiencia duró 40 minutos. El fallo fue dictado en virtud de la Resolución $N^{\circ} 25$ de la Corte Superior de Justicia de 
Huaura que aprobó el acuerdo de Terminación Anticipada suscrito entre la Fiscal Janine Roxana Salazar Cotrina, la procesada Milagros Rosalina Pablo Olórtegui y su abogado Manuel Villacorta Pérez.

Esa fue la primera video audiencia penal realizada en la Corte Superior de Justicia de Huaura, en la que rige el nuevo Código Procesal Penal desde el 1 julio de 2006, que propugna un sistema acusatorio oral.

Como se aprecia, los jueces del Perú, están usando con mayor frecuencia, la tecnología informática y las video audiencias para agilizar y hacer viables los procesos judiciales, lo que constituye una esperanza para el desarrollo, celeridad y eficacia de la administración de justicia.

1 Internet es un concepto que proviene del idioma inglés interconnected, interconectados, y net de network, red. Es una gran red de ordenadores de alcance mundial; sirve para las comunicaciones, negocios, disciplinas y en general para toda actividad del quehacer humano. 